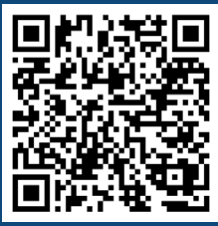

Keywords:

Wood quality

Regression PLS

NIRS

Solid wood

Wood powder

Historic:

Received 27/05/2019

Accepted 28/08/2019

Correspondence: taianaarriel@hotmail.com
Taiana Guimarães Arriel' ${ }^{\text {lat}}$, Fernanda Maria Guedes Ramalho'b , Rebeca Alves Barreto Lima ${ }^{\text {lc }}$, Kelly lapuque Rodrigues de Sousa ${ }^{\text {ld }}$, Paulo Ricardo Gherardi Hein'e, Paulo Fernando Trugilho ${ }^{\text {If }}$

\title{
DEVELOPING NEAR INFRARED SPECTROSCOPIC MODELS FOR PREDICTING DENSITY OF Eucalyptus WOOD BASED ON INDIRECT MEASUREMENT
}

ARRIEL, T. G.; RAMALHO, F. M. G.; LIMA, R. A. B.; SOUZA, K. I. R.; HEIN, P. R. G. TRUGILHO, P. F. Developing near infrared spectroscopic models for predicting density of Eucalyptus wood based on indirect measurement. CERNE, v. 25, n. 3, p.294-300, 2019.

\section{HIGHLIGHTS}

Predictive models were developed for estimating wood density from NIR spectra.

Averaged wood density by trees were associated with NIR spectra measured in the wood of breast height.

More reliable predictions were obtained using mean values per clone in calibration set.

The best model for predicting wood density presented $\mathrm{R}^{2} \mathrm{cv}$ of 0.77 and RMSEcv of I5 $\mathrm{kg} \cdot \mathrm{m}^{-3}$

\section{ABSTRACT}

The objective of this study was to establish multivariate models for the prediction of wood basic density with reference to the values of average density of trees and near infrared (NIR) spectra measured in the breast height. The wood basic density of 39 Eucalyptus clones was determined in the laboratory by means of the mean longitudinal positions of $0 \%, 2 \%, 10 \%, 30 \%, 50 \%$ and $75 \%$ of the commercial height of the tree by the gravimetric method. NIR spectra were recorded using a spectrometer using optical fiber probe and integrating sphere directly on the transverse plane of the solid wood in disks collected from diameter at breast height and later in the sawdust. The performance of the NIR based models was evaluated according to the spectral acquisition method and sample preparation. The results showed that the best model for basic density estimation using indirect measurements was developed from the average spectra per clone measured in solid wood disks ( $\mathrm{R}^{2} \mathrm{cv}$ of 0.77 and RMSEcv of I5 kg. $\left.\mathrm{m}^{-3}\right)$. 


\section{INTRODUCTION}

Wood quality can be defined as the result of the physical and chemical characteristics of the tree or part of the tree that allow it to meet the requirements of properties for different final products (Mitchell, 196I). The evaluation of the quality of the wood is a routine activity in companies that seek rational use of the raw material in the productive processes. Therefore, forest breeding programs have focused on producing varieties of genetic material with characteristics that meet the quality requirements of a particular product.

Wood basic density has been used as an object feature in forest breeding programs (Batista et al., 20I0; Githiomi \& Kariuki, 2010) because of its high heritability (Raymond, 2002) and because it is an easily determined variable (Panshin \& de Zeeuw, 1980). In practice, wood density serves as a reference for classification (Dias et al., 2018), since it has a direct relationship with several other properties, besides influencing different products and co-products (Zobel \& Buijtenen, 1989). Although it is a simple determination feature, obtaining the wood basic density is time consuming and has a high operating cost, depending on the number of samples to be prepared.

Near infrared (NIR) spectroscopy has been pointed out as a promising technique for the evaluation of large numbers of samples, saving time and reagents for predictions (Pasquini, 2018). The technique is based on the interaction of radiation in the near infrared region with matter, resulting in a spectrum of absorption (or reflection) of energy by organic molecules (Brereton, 2003). In general terms, the spectral signature can be used for qualitative and quantitative evaluation of the chemical composition of a particular compound present in the sample, or even to estimate the physicochemical properties of a material (Sandak et al., 20I6). For instance, Rosado et al. (2019) have applied NIR technology for estimating the amount of non-structural carbohydrates in Toona ciliata wood based on spectral signatures.

NIR spectroscopy has been widely used to estimate the basic density of wood. Several studies have reported predictive models based on the NIR spectral signature able to satisfactorily estimate the basic density of Eucalyptus woods and other species (Hein et al., 2009a; Fujimoto et al., 20 I2; Lia et al., 20 I2; Labbé et al., 2013; Lazzarotto et al., 2016; Nascimento et al., 2017).

In these studies, the development of models for predicting the basic density of wood was carried out based on NIR spectra associated to the basic density values of the wood coming from the transverse face of the wood disk (Alves et al., 2012; Baettig et al., 2017; Fujimoto et al., 2012; Pfautsch et al., 20I2), or core (Schimleck et al., 2005; Estopa et al., 2017) removed from the trunk at breast height $(\sim 1.3 \mathrm{~m})$. Thus, most of the predictive models have been based on spectral signatures and basic density values obtained directly in the same sample. However, we do not know the performance of predictive models developed from spectral signatures measured on wooden discs taken at breast height associated with values of average basic density per tree or clones. Thus, the objective of this study was to establish multivariate models for the prediction of wood basic density with reference to the values of average density of trees and NIR spectra measured in the breast height region.

This new procedure is particularly interesting for those companies that have plantations with clones whose average wood density is known and who wish to apply the NIR technique to select superior individuals. Selection may be based on average values per tree, taking into account all the spatial variation existing along the shaft, and not only in estimating the wood basic density at a specific region of the tree.

\section{MATERIAL AND METHODS}

\section{Material origin and sampling}

In this study thirty-nine (39) Eucalyptus spp. clones, $8 \mathrm{I}$ months of age, were used. The trees originated from a clonal test located in Curvelo in the central region of the state

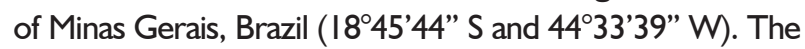
planting was installed at a spacing of $3 \times 3 \mathrm{~m}$, at an altitude of $690 \mathrm{~m}$ and with annual precipitation of $1308.3 \mathrm{~mm}$.

Three trees of medium diameter per genetic material were selected and felled, totaling 1 I 7 trees. In the selected trees, discs $2.5 \mathrm{~cm}$ thick were removed at six longitudinal sampling positions, at $0 \%$ (base); $2 \%$; $10 \% ; 30 \% ; 50 \%$ and $75 \%$ of the commercial height $(\mathrm{CH})$, considered up to the diameter with bark of 4 $\mathrm{cm}$, to determine the mean basic density of the tree by conventional method. An extra disk was obtained from the conventional diameter at breast height (DBH) position to obtain the NIR spectra (Figure I).

\section{Sample preparation}

The discs removed at breast height had their cross-sectional surface sanded using an electric sander with sandpaper number 40 and 120 . The discs were conditioned in an air-conditioned chamber $(60 \%$ relative humidity and $20^{\circ} \mathrm{C}$ ) until moisture stabilization at $14 \%$ before acquisition of the NIR spectra in the solid wood condition. Subsequently, the disks were cut in the middle for removal of wood samples. These samples were ground, classified through 40 and 60 mesh sieves 


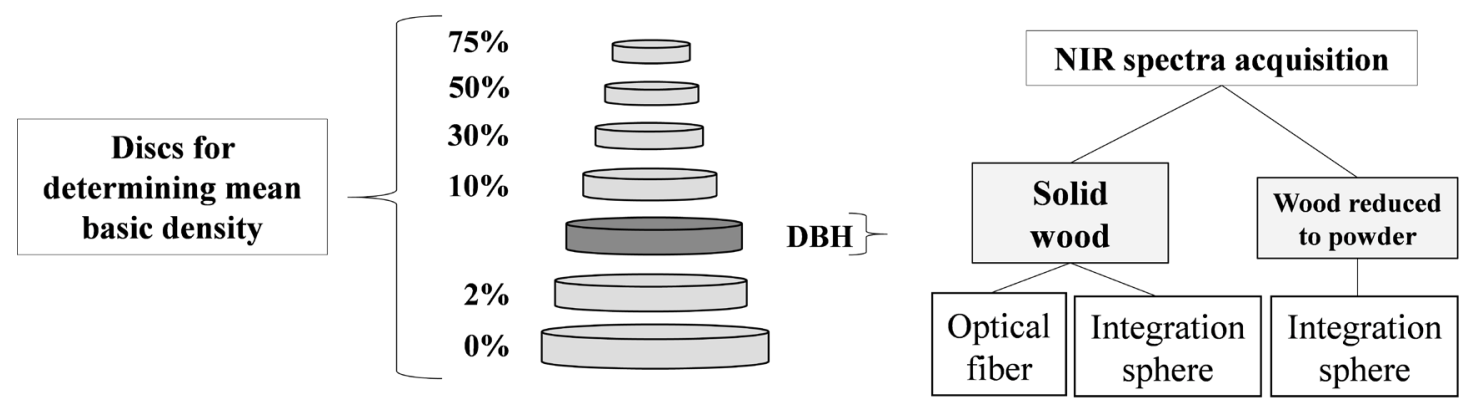

FIGURE I Sampling for NIR spectra acquisition and determination of the wood basic density by conventional method..

and conditioned in the air conditioned chamber until moisture stabilization for subsequent use to obtain the spectra in sawdust.

\section{NIR spectra acquisition and multivariate analysis}

After the preparation of the two types of samples (solid wood and sawdust), on the solid sample (crosssectional area) the integration sphere and the optical fiber probe were used as pathways to obtain the NIR spectra, whereas in the milled wood only the integration sphere path was used. NIR spectra were obtained from all evaluated trees and clones. In order to obtain the spectra, the Bruker FT-NIR spectrometer (model MPA, Bruker Optik GmbH, Ettlingen, Germany) was used in the spectral range of $I 2,500$ to $4,000 \mathrm{~cm}^{-1}$ with a spectral resolution of $8 \mathrm{~cm}^{-1}$ in diffuse reflection mode, with 16 scans per sample, in conjunction with the Opus 4.2 program. Spectra at wavelengths from $9000 \mathrm{~cm}^{-1}$ to 4000 $\mathrm{cm}^{-1}$ were analyzed in the program The Unscrambler 9.7 (CAMO AS, Norway), applying principal component analysis (PCA) and partial least squares regression (PLS-R) for predicting wood density. NIR spectra were evaluated in two manners, one with all II 7 spectra (39 clones and three trees) and another considering the mean value of the 39 evaluated clones. Treatments performed in the spectra were: exclusion of wavelengths with presence of noise, removal of anomalous samples (outliers) and first derivative (13-point filter and a second-order polynomial using Savitzky-Golay algorithm), in search of improvement in the performance of the models. The best models were selected based on the coefficient of determination of calibration $\left(R^{2} c\right)$ and cross validation $\left(R^{2} c v\right)$, root mean standard of calibration error (RMSEc) and cross validation (RMSEcv), number of latent variables (LV) used in the models and the ratio to performance deviation (RPD) as suggested by Estopa et al. (2017).

Determination of basic density by conventional method

The disks removed at the longitudinal sampling positions, except at breast height, were subdivided into wedges passing through the medulla and two opposing wedges were used to determine the wood basic density. The wood basic density was determined according to standard NBR II94I (ABNT, 2003). The mean basic density of the tree was considered the arithmetic mean of the longitudinal sampling positions.

\section{RESULTS}

\section{NIR Spectra}

The NIR spectra acquired by the integrating sphere and fiber optic probes are shown in Figure $2 a$ without treatments and in Fig. $2 b$ treated by means of the first derivative. The spectra present absorption bands as a function of the wavelengths, in which those obtained by means of the sphere obtained higher absorbance values than those acquired by means of the fiber.
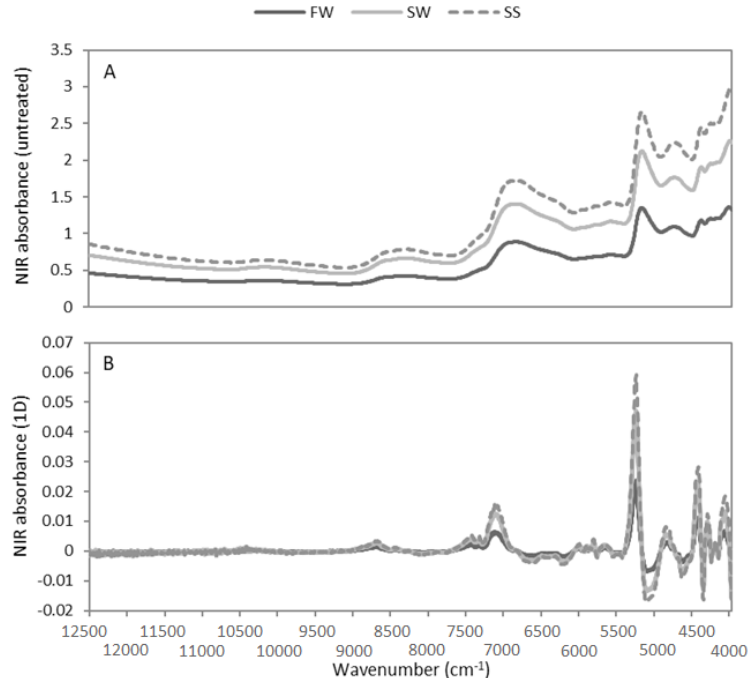

FIGURE 2 Original NIR spectra $(A)$ and treated by first derivative (B) recorded from wood and sawdust. FW: Spectra collected using optical fiber probe on wood. SW: Spectra collected using integrating sphere on wood. SS: Spectra collected using integrating sphere in sawdust. 


\section{Exploratory Analysis}

Scores obtained by PCA from the spectra collected on the wood disks by means of the integrating sphere and optical fiber probe are presented in the two-dimensional graph of Figure 3. The first principal component (PC I) explains $99.38 \%$ of the variation of the data while PC 2 explains $0.48 \%$, totaling $99.86 \%$ of the data variation.

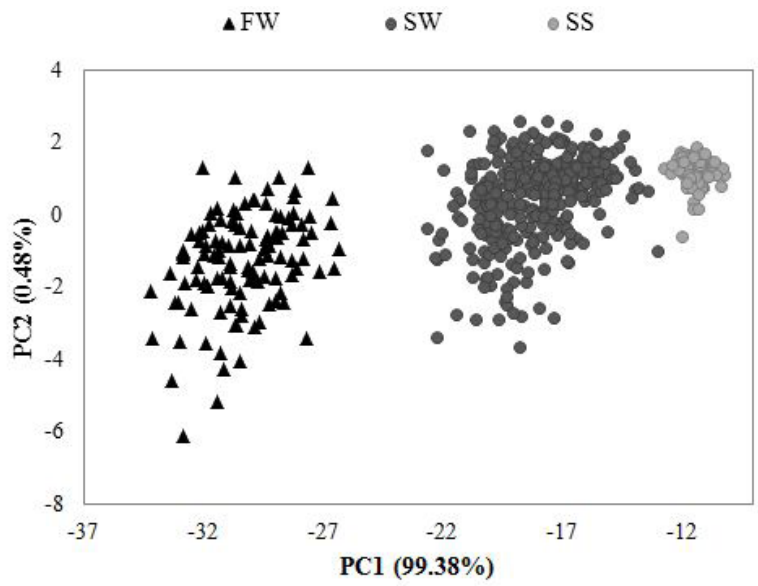

FIGURE 3 PCA scores made with wood and sawdust spectra collected by integration sphere and optical fiber. FW: Spectra collected using optical fiber probe on wood. SW: Spectra collected using integration sphere on wood. SS: Spectra collected using integration sphere on sawdust.

Estimating wood density by PLS-R models

The basic density of the wood by tree, determined in the laboratory, presented average, minimum and maximum values of $524.30 \mathrm{~kg} \cdot \mathrm{m}^{-3}, 444.65 \mathrm{~kg} \cdot \mathrm{m}^{-3}$ and $578.19 \mathrm{~kg} . \mathrm{m}^{-3}$, respectively. Table I presents the statistics associated with the prediction models of the wood basic density of the clonal materials based on the solid and ground wood spectra. The dispersion of the measured and predicted values by NIR is shown in Figure 4.

TABLE I Descriptive statistics of the data groups.

\begin{tabular}{ccccccccc}
\hline Spectra & $\mathrm{N}$ & $\mathrm{MT}$ & $\mathrm{R}^{2} \mathrm{c}$ & $\mathrm{RMSEc}$ & $\mathrm{R}^{2} \mathrm{cv}$ & $\mathrm{RMSEcV}$ & $\mathrm{LV}$ & $\mathrm{RPD}$ \\
\hline FW & -I out/Id & 0.38 & 25.00 & 0.32 & 26.00 & 2 & $\mathrm{I} .24$ \\
SW & $\mathrm{II}$ & -2 out/Id & 0.57 & 20.00 & 0.55 & 21.00 & 3 & 1.54 \\
SS & Id & 0.54 & 21.00 & 0.43 & 24.00 & 5 & 1.33 \\
\hline FW & - & 0.48 & 22.00 & 0.40 & 23.00 & 2 & 1.35 \\
SW & 39 & -3 out & 0.89 & 10.00 & 0.77 & 15.00 & 8 & 2.07 \\
SS & - & 0.54 & 21.00 & 0.38 & 25.00 & 8 & 1.24 \\
\hline
\end{tabular}

FW: Spectra collected using optical fiber probe on wood. SW: Spectra collected using integration sphere on wood. SS: Spectra collected using integration sphere on sawdust. N: Number of samples; MT: Mathematical treatment; out: Outlier; Id: First derivative; $\mathrm{R}^{2} \mathrm{c}$ : Coefficient of determination of the calibration; RMSEc: Root mean square error of the calibration; $\mathrm{R}^{2} \mathrm{cv}$ : Coefficient of determination of the cross validation; RMSEcv: Root mean square error of the cross-validation standard error; VL: Number of latent variables; RPD: ratio of the deviation performance.

\section{DISCUSSION}

In Figure 2, both for the untreated spectra (Figure 2A) and for the treated spectra (Fig. 2B), the absorption bands are more prominent from the 9000 $\mathrm{cm}^{-1}$ to $4000 \mathrm{~cm}^{-1}$ wavelength, which evidences the greater interaction of near infrared radiation with the functional groups of wood compounds in that region. According to Lestander et al. (2009), in biomass NIR radiation interacts with $\mathrm{C}-\mathrm{H}, \mathrm{C}-\mathrm{O}, \mathrm{C}-\mathrm{O}-\mathrm{H}, \mathrm{C}=\mathrm{C}$ bonds and also with the water always present in the material. By means of the first derivative treatment (Fig. 2B) there was a modification in the behavior of the spectra evidencing the absorption bands at the wavelengths in the near infrared. The higher absorbance intensity in the integrating sphere spectra may be due to the higher light beam incidence area obtained with the use of this spectral acquisition pathway, it is larger than the optical fiber area. It is not possible to perform an interpretation of the collected data only through the visualization of the spectra, requiring statistical analysis.

The PCA scores (Figure 3 ) are distinguished by three groups: spectra obtained by means of fiber on solid wood, obtained by means of the sphere on wood and by the sphere on wood reduced to powder. The data collected by the sphere are concentrated more homogeneously, especially the sawdust data. With this, it can be inferred that the sphere is able to collect the information of the material more efficiently than the fiber. Perhaps this is possible because the sphere has a larger diameter than the fiber, thus has a larger area of contact with the sample and greater representativeness of the existing variations. Moreover the sawdust wood is more homogeneous than solid wood. NIR spectra measured in solid wood are influenced by local heterogeneities, while ground wood is more homogeneous (Hein et al., 2010). However, the milling process can be a hindrance to processing large numbers of samples. Regarding the particle size, these same authors find greater differences between the solid and powder spectra than between the spectra measured in different particle size of wood powders.

For the prediction of basic density by partial least squares regression (Table I), the best result was observed in the solid wood with reading via integrating sphere, using the average per clone, which presented coefficient of determination of the cross-validation $\left(R^{2} \mathrm{cv}\right)$ of 0.77 and performance to deviation ratio (RPD) of 2.07. The lowest $R^{2} c v$ values were obtained by optical fiber probe n solid wood, with $R^{2} c v$ of 0.38 and an RPD of 1.24 , from the data with the three replicates. By observing the dispersion of the values measured in the laboratory and predicted by the NIR (Figure 4), the results obtained by 

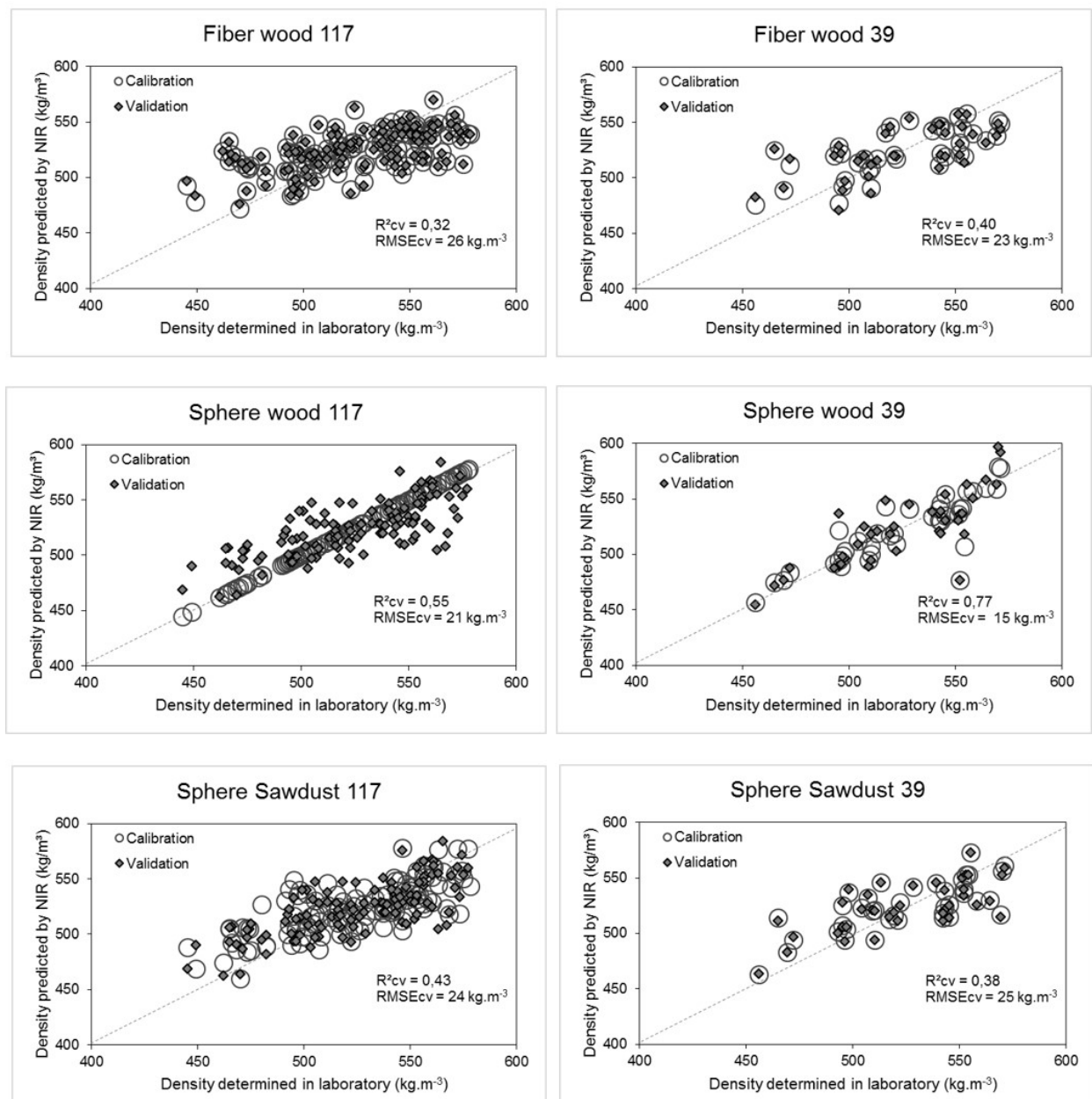

FIGURE 4 Wood basic density values estimated by models based on spectra obtained by the integration sphere and optical fiber on solid wood and sawdust determined in the laboratory.

means of the fiber were also the ones that have worse association. The integration sphere was able to collect more useful information, during the acquisition of wood spectra, for predicting the basic density than fiber optics, a fact also reported by Costa et al. (20/8). Thus, it can be inferred that it is more efficient and its preference for use must be taken into account. Hein et al. (2010) have observed the influence of sample preparation on chemical properties estimation of Eucalyptus urophylla by NIR spectroscopy, in which the best calibrations were developed using wood dust spectra. This study shows that for basic density the best calibrations are obtained using solid wood spectra.

Viana et al. (2010) have evaluated Eucalyptus clones at three years of age to develop models for predicting the wood basic density, and the samples for analysis in the NIR were collected at $1.30 \mathrm{~m}$ from the soil for calibration based on laboratory data of the density (similar to this work) and the disk itself at the DBH. The authors presented calibrations for basic density estimation at the $D B H$ with $R^{2} \mathrm{cv}$ ranging from 0.73 to 0.86 and RPD of I.4 to 2.0 and calibrations performed from mean tree density (DBM) with $R^{2} \mathrm{cv}$ ranging from 0.56 to 0.97 and RPD from I.I to 4.7.

Baettig et al. (2017) have evaluated the efficiency of the NIR technique to predict basic density in the cross section of discs at different positions in the marrow to bark direction of Pinus radiata through the optical fiber probe using basic density reference values obtained by $X$-ray and found $R^{2} \mathrm{cv}$ varying from $0.9 \mathrm{I}$ to 0.93 . Kothiyal et al. (20I4) used the NIRS technique to calibrate models to predict the basic density of green wood (27-30\% moisture) on the radial and tangential faces of Eucalyptus tereticornis wood from 10 to 12 years of age. The authors present models with $R^{2} c v$ from 0.74 to 0.77 and RPD from 2.06 to 2.38 for the integrating sphere; and values 
from 0.64 to 0.77 and 2.31 to 2.46 for $R^{2} c v$ and RPD, respectively, for the optical fiber.

Considering the indirect method used in this study, the results are promising, that is, the practicality of the method justifies the use. In other works that use the NIR spectroscopy technique to predict wood properties, they usually use the same position (same sample) in the bole for conventional laboratory analysis and for reading in the spectrometer, as in Hein $(2010,2012)$ and Hein et al. (2009). According to Schimleck et al. (2003) calibrations in NIR with RPD equal to or higher than I.5 are sufficient for initial readings in order to select young trees with potential for use of the technique, and the higher the RPD value, the better the fit of the model (Fujimoto et al., 2008).

\section{CONCLUSION}

Considering the indirect sampling method (spectrum obtained on the DBH disk and reference data obtained from the mean in the longitudinal portions of the trunk) and using clonal materials, i.e. low variability it was possible to develop models for fast prediction of basic wood density. The best performance of predictions through the PLS regression for the basic density was obtained through the mean per clone, which showed better performance than the prediction performed from the data with the replicates (three trees) per clone. The acquisition path that allowed this result was the reading by the integration sphere realized in the solid wood (DBH disk), a result that agrees with the analysis of main components that obtained greater homogeneity in the dispersion of the spectra scores obtained by this acquisition path. Considering that training models process is performed only once and that it is possible to capture tree representativeness in terms of wood density by collecting spectra only at breast height, using this approach is worth, rapid and reliable for initial screening. The practicality of this approach justifies its use since it optimizes the time of analyzes in the laboratory and the collection of the trees in the field.

\section{ACKNOWLEDGEMENTS}

This study was financed in part by the Coordenação de Aperfeiçoamento de Pessoal de Nível Superior - Brasil (CAPES) - Finance Code 00I, by the Conselho Nacional de Desenvolvimento Científico e Tecnológico (CNPq: grants n. 158839/2015-3 and 405085/2016-8), by the Fundação de Amparo à Pesquisa do Estado de Minas Gerais (FAPEMIG) and Plantar S/A. P.R.G. Hein was supported by CNPq grants (process no. 303675/2017-9).

\section{REFERENCES}

ABNT (ASSOCIAÇÃO BRASILEIRADE NORMAS TÉCNICAS), 2003. NBR I I94I: Madeira: determinação da densidade básica. ABNT, Rio de Janeiro.

ALVES, A; SANTOS, A; ROZENBERG, P; PÂQUES, L.E.; CHARPENTIER, J.P.; SCHWANNINGER, M; RODRIGUES, J.A. common near infrared-based partial least squares regression model for the prediction of wood density of Pinus pinaster and Larix $\times$ eurolepis. Wood Sci Technol, v. 46, p. I57-175, 2012.

BAETTIG, R; CORNEJO, J; GUAJARDO, J. Evaluation of intraring wood density profiles using NIRS: comparison with the X-ray method. Ann For Sci, v. 74, p. I-I3, 2017.

BATISTA, D.C.; KLITZKE R.J.; TABORDA, C.V.S. Densidade básica e retratibilidade da madeira de clones de três espécies de Eucalyptus. Cienc Florest, v. 20, p. 665-674, 2010.

BRERETON, R.G. Chemometrics: data analysis for the laboratory and chemical plant. J. Wiley, 2003. 489p.

COSTA, E.V.S.; ROCHA, M.F.V.; HEIN, P.R.G.; AMARAL, E.A.; SANTOS, L.M.; BRANDÄO, L.E.V.S.; TRUGILHO, P.F. Influence of spectral acquisition technique and wood anisotropy on the statistics of predictive NIR-based models for wood density. J Near Infrared Spectrosc, v. 26, p. I06-I I6, 2018.

DIAS, A.C.C.; MARCHESAN, R.; ALMEIDA, V.C.; MONTEIRO, T.C.; MORAES, C.B. Relação entre a densidade básica e as retrações em madeira de teca. Rev Cienc Mad, v. 9, p. 37-44, 2018.

ESTOPA, R.A.; MILAGRES, F.R.; OLIVEIRA, R.A.; HEIN, P.R.G. NIR spectroscopic models for phenotyping wood traits in breeding programs of Eucalyptus benthamii. Cerne, v. 22, p. 367-375, 2017.

FUJIMOTO, T.; KOBORI, H.; TSUCHIKAWA, S. Prediction of wood density independent of moisture conditions using near infrared spectroscopy. J Near Infrared Spectrosc, v. 20, p. $353,2012$.

FUJIMOTO, T.; KURATA, Y.; MATSUMOTO, K.; TSUCHIKAWA, S. Application of near infrared spectroscopy for estimating wood mechanical properties of small clear and full lenght lumber specimens. J Near Infrared Spectrosc, v. 16, p. 529-537, 2008.

GITHIOMI, J.K.; KARIUKI, J.G. Wood basic density of Eucalyptus grandis from plantations in Central Rift Valley, Kenya: variation with age, height level and between sapwood and heartwood. J Trop For Sci, v. 22, p. 28I-286, 2010.

HEIN, P.R.G. Multivariate regression methods for estimating basic density in Eucalyptus wood from near infrared spectroscopic data. Cerne, v. 16, p. 090-096, 2010.

HEIN, P.R.G. Estimating shrinkage, microfibril angle and density of Eucalyptus wood using near infrared spectroscopy. J Near Infrared Spectrosc, v. 20, p. 427-436, 2012. 
HEIN, P.R.G.; LIMA, J.T.; CHAIX, G. Effects of sample preparation on NIR spectroscopic estimation of chemical properties of Eucalyptus urophylla S.T. Blake wood. Holzforschung, V. 64, p. 45-54, 2010.

HEIN, P.R.G.; LIMA, J.T.; CHAIX, G. Robustness of models based on near infrared spectra to predict the basic density in Eucalyptus urophylla wood. J Near Infrared Spectrosc, v. I7, p. I4I-I50, 2009a.

HEIN, P.R.G; CAMPOS, A.C.M.; TRUGILHO, P.F; LIMA, J.T.; CHAIX, G. Near infrared spectroscopy for estimating wood basic density in Eucalyptus urophylla and Eucalyptus grandis. Cerne, v. I5, p. I33-I4I, 2009.

KOTHIYAL, V.; RATURI, A.; JAIDEEP; DUBEY, Y.M. Enhancing the applicability of near infrared spectroscopy for estimating specific gravity of green timber from Eucalyptus tereticornis by developing composite calibration using both radial and tangential face of wood. Eur J Wood Wood Prod, v. 72, p. II-20, 2014

LABBÉ, R.; DROPPELMANN, F; BALOCCHI, C.; PEREDO, $M$. Variación de la densidad de la madera y rendimiento pulpable en clones de Eucalyptus globulus evaluado con espectroscopía de infrarrojo cercano. Bosque, v. 34, p. $3-4,2013$.

LAZZAROTTO, M.; NETIPANYJ, R.R.; MAGALHÃES, W.L.E.; AGUIAR, A.V. Espectroscopia no infravermelho próximo para estimativa da densidade básica de madeiras de Pinus. Rev Cienc Mad, v. 7, p. II9-126, 2016.

LESTANDER, T.A.; JOHNSSON, B.; GROTHAGE, M. NIR techniques create added values for the pellet and biofuel industry. Bioresource Technol., v. I00, p. I589-1594, 2009.

LIA, Y.; LIA, P.; JIANGB, L. Prediction of larch wood density by near-infrared spectroscopy and an optimal BP neural network using coupled GA and RSM. J Infor Comput Sci, v. I3, p. 3783-3794, 2012.

MITCHELL, H.L. A concept of intrinsic wood quality and non-destructive methods for determining quality in standing timber. For Prod Lab, Madison. 1961.

NASCIMENTO, C.C.; BRASIL, M.M.; NASCIMENTO, C.S.; BARROS, S.V.S. Estimativa da densidade básica da madeira de Eschweilera odora (Poepp.) Miers por espectroscopia no infravermelho próximo. Rev Cienc Mad, v. 8, p. 42-53, 2017.
PANSHIN, A.J.; de ZEEUW, C. Textbook of wood technology. Mc Graw Hill, New York, 1980.

PASQUINI, C. Near infrared spectroscopy - A mature analytical technique with new perspectives - A review. Anal Chim Acta, v. 1026, p. 8-36, 2018.

PFAUTSCH, S.; MACFARLANE, C.; EBDON, N.; MEDER, R. Assessing sapwood depth and wood properties in Eucalyptus and Corymbia spp. using visual methods and near infrared spectroscopy (NIR). Trees - Struct Funct, v. 26, p. 963-974, 2012.

RAYMOND, C.A. Genetics of Eucalyptus wood properties. Ann For Sci., v. 59, p. 525-53I, 2002.

ROSADO, L.R .; TAKARADA, L.M ; ARAÚJO, A.C.C .; SOUZA, K.R.D ;; HEIN, P.R.G ; ROSADO, S.C.S .; GONÇALVES, F.M.A. Near infrared spectroscopy: rapid and accurate analytical tool for prediction of non-structural carbohydrates in wood. CERNE, v. 25, p. 84-92, 2019

SANDAK, J.; SANDAK, A.; MEDER, R. Assessing trees, wood and derived products with near infrared spectroscopy: Hints and tips. J Near Infrared Spectrosc, v. 24, p. 485-505, 2016

SCHIMLECK, L.R.; JONES, P.D.; PETER, G.F; DANIELS, R.F.; CLARK, A. Success in using near infrared spectroscopy to estimate wood properties of Pinus taeda radial strips not due to autocorrelation. J Near Infrared Spectrosc, v. I3, p. 47-5I, 2005.

SCHIMLECK, L.R.; MORA, C.; DANIELS, R.F. Estimation of the physical wood properties of green Pinus taeda radial samples by near infrared spectroscopy. Can J Forest Res, v. 33, p. 2297-2305, 2003.

VIANA, L.C.; TRUGILHO, P.F; HEIN, P.R.G.; SILVA, J.R.M.; LIMA, J.T. Modelos de calibração e a espectroscopia no infravermelho próximo para predição das propriedades químicas e da densidade básica da madeira de Eucalyptus. Cienc Florest, v. 20, p. 367-376, 2010.

ZOBEL, B.J.; BUIJTENEN, J.P. Wood Variation: Its Causes and Control. Springer, 1989. 